\title{
Laparoscopic Cholecystectomy in Kartagener Syndrome
}

\author{
${ }^{1}$ Rahul Gupta, ${ }^{2}$ Harjeet Singh, ${ }^{3}$ Ganga R Verma
}

\begin{abstract}
Kartagener syndrome is a rare autosomal recessive disorder in which there is situs inversus involving abdominal or thoracic viscera or both. Anatomy of the abdominal organs in such a patient is distorted making laparoscopic surgery very difficult. A 45-year-old lady, a known case of Kartagener syndrome, presented with epigastric pain. Ultrasound of abdomen revealed situs inversus with mild hepatomegaly and multiple gallbladder calculi. Magnetic resonance pancreatocholangiography (MRCP) confirmed situs inversus totalis with cholelithiasis and mild central intrahepatic biliary dilatation. Patient was treated successfully with laparoscopic cholecystectomy.
\end{abstract}

Keywords: Bronchiectasis, Gallstones, Situs inversus.

How to cite this article: Gupta R, Singh H, Verma GR. Laparoscopic Cholecystectomy in Kartagener Syndrome. J Postgrad Med Edu Res 2017;51(4):192-194.

Source of support: Nil

Conflict of interest: None

\section{INTRODUCTION}

Laparoscopic cholecystectomy is one of the commonest surgical procedures performed worldwide for gallstone disease. Situs inversus is a rare autosomal recessive disorder in which there is complete rotation of abdominal or thoracic viscera or both to the opposite side. ${ }^{1}$ Situs inversus totalis can be either alone or in combination with chronic sinusitis and bronchiectasis called as Kartagener syndrome. ${ }^{2}$ There are very few reports of laparoscopic surgery in Kartagener syndrome because of associated respiratory disorders. ${ }^{3,4}$ Anatomy of the abdominal organs in such a patient is distorted, making laparoscopic surgery difficult. We report a rare case of Kartagener syndrome with gallstone disease managed successfully by laparoscopic cholecystectomy.

\section{CASE REPORT}

A 45-year-old lady, a known case of Kartagener syndrome, presented with right hypochondriac pain

\footnotetext{
${ }^{1}$ Ex-Senior Resident, ${ }^{2}$ Assistant Professor, ${ }^{3}$ Senior Professor

${ }^{1-3}$ Department of General Surgery, Postgraduate Institute of Medical Education and Research, Chandigarh, India

Corresponding Author: Ganga R Verma, Senior Professor Department of General Surgery, Postgraduate Institute of Medical Education and Research, Chandigarh, India, Phone: +01722756627, e-mail: grverma@gmail.com
}

radiating to back since 6 months. She had past history of bilateral breast cancer for which she underwent breast conservative surgery with adjuvant chemoradiation. She was a known asthmatic with bronchiectasis and hypertension on bronchodilators and antihypertensives. Per abdominal examination was unremarkable. Chest radiogram showed situs inversus with bronchiectasis. Ultrasound of abdomen revealed situs inversus with mild hepatomegaly and multiple gallbladder calculi. Magnetic resonance pancreatocholangiography confirmed situs inversus totalis with cholelithiasis. Gallbladder was located in midline, raising suspicion of incomplete rotation (Figs 1 and 2). Liver function tests were normal. Preoperatively, patient was optimized with bronchodilators, antihypertensives, incentive spirometry, and chest physiotherapy.

Laparoscopic cholecystectomy was performed with the conventional 4-trocar technique. The operative team and laparoscopic devices were located like in normal laparoscopic cholecystectomy. One 10-mm trocar was inserted into the abdominal cavity in the infraumbilical position. At laparoscopic abdominal exploration, the positions of organs were found to be reversed. Liver was located in the left hypochondrium and the gallbladder was present just to the right of falciform ligament suggestive of incomplete rotation. To facilitate dissection, a 10-mm trocar was inserted at the Palmer's point on the left side. A 5-mm trocar was inserted medial to right midclavicular line and a second 5-mm trocar was also

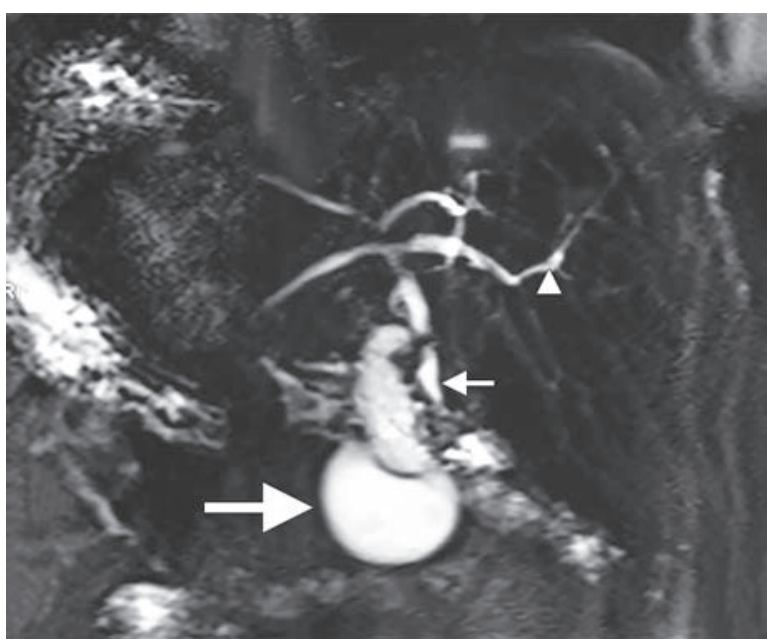

Fig. 1: The MRCP showing left-sided liver with prominent intrahepatic biliary radicles (arrow head), gallbladder (thick arrow) located in midline and cystic duct joining common bile duct (thin arrow) from right side 


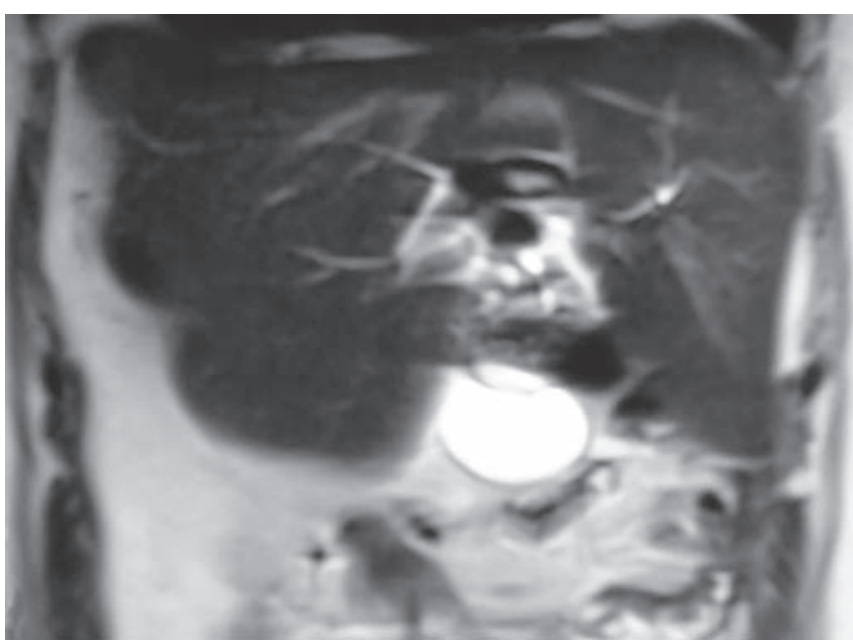

Fig. 2: Magnetic resonance imaging of abdomen in coronal view showing left-sided liver with distended gallbladder hanging from its inferior border

inserted medial to right anterior axillary line under the view of laparoscope. Calot's anatomy was normal with single cystic artery and cystic duct, which were clipped and cut (Fig. 3). There were two accessory biliary ducts of about $2 \mathrm{~mm}$ in diameter seen arising from gallbladder fossa entering into the gallbladder. They were doubly clipped and cut. Gallbladder was dissected and removed from left hypochondriac port. Patient tolerated the procedure well and had an uneventful postoperative recovery.

\section{DISCUSSION}

Kartagener syndrome is a rare disorder comprising situs inversus, sinusitis, and brochiectasis. ${ }^{3}$ Only two cases of such patients requiring cholecystectomy for gallstone disease have been reported in English literature. ${ }^{3,4}$ In one patient, laparoscopic cholecystectomy was carried out $^{3}{ }^{3}$ while in another case, open cholecystectomy was done under regional anesthesia due to cardiorespiratory disorders. In this disorder, there is a $270^{\circ}$ clockwise rotation instead of normal $270^{\circ}$ anticlockwise rotation of the developing thoracoabdominal organs during fetal life resulting in mirror image positioning of the abdominal and thoracic viscera. ${ }^{5}$ This condition may be associated with other congenital anomalies, such as biliary atresia and congenital heart disease. ${ }^{2,6}$ But there is no evidence to suggest that these patients are predisposed to cholelithiasis. Diagnosis of gallstone disease is often delayed in patients without known history of situs inversus because of atypical location of pain.

Presence of cardiorespiratory diseases puts these patients at high risk for perioperative complications. Skilled anesthesist team is required as these patients are likely to have difficult endotracheal intubation, difficulty in administering neuraxial anesthesia due to spinal

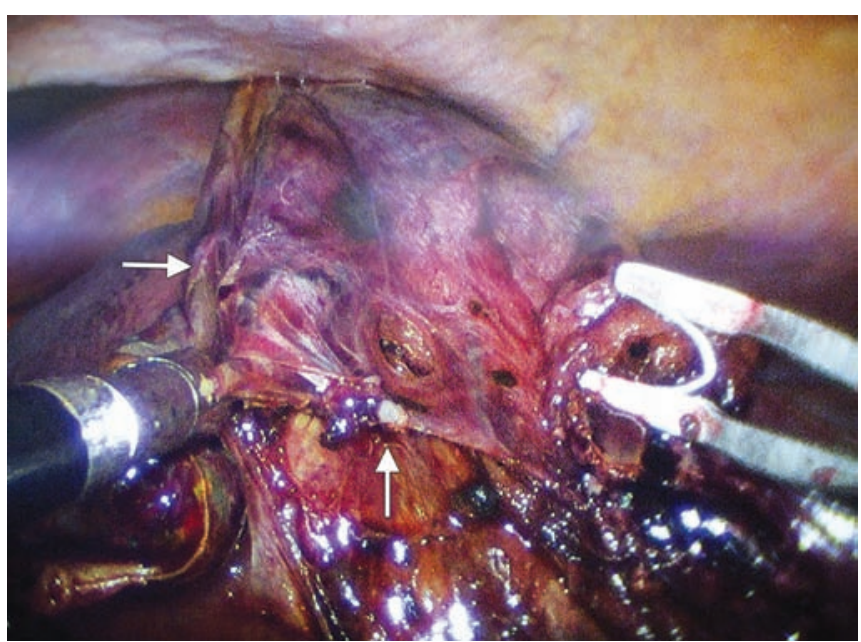

Fig. 3: Calot's anatomy: gallbladder (horizontal arrow) and cystic duct (vertical arrow) joining common hepatic duct from right side

deformities, and require appropriate selection of anesthetic drugs for induction and maintenance of general anesthesia due to associated cardiovascular anomalies. ${ }^{7}$ Postoperatively, these patients need aggressive chest physiotherapy as they tend to retain chest secretions due to ciliary dyskinesia. ${ }^{8}$

Laparoscopic cholecystectomy is a technically demanding procedure in situs inversus totalis. Technical modifications are required to perform this procedure successfully. Salama et $\mathrm{al}^{9}$ recommended that contrary to the position of operative surgeon and the assistant surgeons in conventional laparoscopic cholecystectomy, the position may need to be reversed; however, in the index patient, as the gallbladder was on right side of falciform ligament in midabdomen, by putting operating port at Palmer's point in left hypochondrium and shifting other ports toward the right, we could perform the surgery by standing on left side of patient. Another technical difficulty experienced by the operating surgeon is the direction of cystic and common bile duct, which lies toward the right of gallbladder; because of mirror image anatomy of gallbladder, dissection of Calot's triangle with left hand through epigastric port becomes challenging. If the assistant surgeon is made to retract the Hartmann's pouch through left midclavicular port, the right-handed surgeon can dissect the Calot's triangle with right hand through epigastric port. ${ }^{10}$ In this patient, as the gallbladder was on the right side of porta hepatis, we did not have this problem. Use of special laparoscopic instruments like ultrasonically activated coagulating scissors for dissection can be beneficial in such cases as shown in previous reports. ${ }^{1}$

To conclude, laparoscopic cholecystectomy in Kartagener syndrome can be safely performed by an experienced surgeon and skilled anesthetist. Degree of 
malrotation of gut dictates the position of surgeon and assistant during surgery.

\section{REFERENCES}

1. Pitiakoudis M, Tsaroucha AK, Katotomichelakis M, Polychronidis A, Simopoulos C. Laparoscopic cholecystectomy in a patient with situs inversus using ultrasonically activated coagulating scissors. Report of a case and review of the literature. Acta Chir Belg 2005 Feb;105(1):114-117.

2. Kobus C, Targarona EM, Bendahan GE, Alonso V, Balagué C, Vela S, Garriga J, Trias M. Laparoscopic surgery in situs inversus: a literature review and a report of laparoscopic sigmoidectomy for diverticulitis in situs inversus. Langenbecks Arch Surg 2004 Oct;389(5):396-399.

3. Campos L, Sipes E. Laparoscopic cholecystectomy in a 39 year old female with situs inversus. J Laparoendosc Surg 1991;1(2): 123-125, discussion 126.

4. Kapoor R, Dhanoa J, Afzal L, Verghese M, Jacob S. Cholecystectomy under regional anesthesia in a patient with total Kartagener's syndrome. Indian J Gastroenterol 1997 Apr;16(2):64-65.
5. Song JY, Rana N, Rottman CA. Laparoscopic appendicectomy in a female patient with situs inversus: case report and literature review. JSLS 2004 Apr-Jun;8(2):175-177.

6. Piryani RM, Shukla A, Prasad DN, Kohli SC, Shrestha G, Singh D. Situs inversus with dextrocardia with multiple cardiac lesions in adult. Kathmandu Univ Med J (KUMJ) 2007 Apr-Jun;5(2):247-249.

7. Bajwa SJ, Kulshrestha A, Kaur J, Gupta S, Singh A, Parmar SS. The challenging aspects and successful anaesthetic management in a case of situs inversus totalis. Indian J Anaesth 2012 May-Jun;56(3):295-297.

8. Rubin BK. Immotile cilia syndrome (primary ciliary dyskinesia) and inflammatory lung disease. Clin Chest Med 1988 Dec;9:657-668.

9. Salama IA, Abdullah MH, Houseni M. Laparoscopic cholecystectomy in situs inversus totalis: feasibility and review of literature. Int J Surg Case Rep 2013 May;4(8):711-715.

10. Arya SV, Das A, Singh S, Kalwaniya DS, Sharma A, Thukral BB. Technical difficulties and its remedies in laparoscopic cholecystectomy in situs inversus totalis: a rare case report. Int J Surg Case Rep 2013 Jun;4(8):727-730. 